\title{
International Expert Consensus on Sutureless and Rapid Deployment Valves in Aortic Valve Replacement Using Minimally Invasive Approaches
}

\author{
Mattia Glauber, MD, * Simon C. Moten, MD, †ugenio Quaini, MD, * Marco Solinas, MD,* \\ Thierry A. Folliguet, MD, FACS, § Bart Meuris, MD, PhD,// Antonio Miceli, MD, PhD, * \\ Peter J. Oberwalder, MD, I Manfredo Rambaldini, MD, \# Kevin H. T. Teoh, MD, ** \\ Gopal Bhatnagar, MD, $+\dagger$ Michael A. Borger, MD, PhD, $+\neq$ Denis Bouchard, MD, $\S \S$ \\ Olivier Bouchot, MD,/// Stephen C. Clark, FRCS (CTh), II Otto E. Dapunt, MD, PhD,\#\# \\ Matteo Ferrarini, MD, * Theodor J. M. Fischlein, MD, *** Guenther Laufer, MD, $+\dagger \dagger$ \\ Carmelo Mignosa, MD, $+\neq$ Russell Millner, MD, $\S \S$ Philippe Noirhomme, MD,//I/I
}

Steffen Pfeiffer, MD, $+\dagger+$ Xavier Ruyra-Baliarda, MD, III Malakh Lal Shrestha, MBBS, PhD,\#\#\#

Rakesh M. Suri, MD, DPhil, **** Giovanni Troise, MD, $+\dagger \dagger$ and Borut Gersak, MD, PhD + *t*

\begin{abstract}
Objective: To define the benefit of sutureless and rapid deployment valves in current minimally invasive approaches in isolated aortic valve replacement.
\end{abstract}

Accepted for publication February 29, 2016

From the *Istituto Clinico Sant' Ambrogio, Clinical \& Research Hospital IRCCS-Gruppo Ospedaliero San Donato, Milano, Italy; †Austin Health and Royal Melbourne Hospital, Melbourne, Australia; †Ospedale del Cuore G. Pasquinucci, Fondazione Toscana G. Monasterio, Massa, Italy; §Centre Hospitalo-Universitaire Brabois ILCV, Nancy, France; |U.Z. Gasthuisberg, Leuven, Belgium; - Unniversitat Kilinik, Graz, Austria; \#Ospedale di Mantova, Mantua, Italy; **Southlake Regional Health Centre, McMaster University, Hamilton, Canada; ††Trillium Cardiovascular Associates, Mississauga, Ontario, Canada; \$tColumbia University Medical Center, New York, NY USA $\S \S$ University of Montreal, Montreal, Quebec, Canada; |||CHU le Bocage, Dijon, France; qqFreeman Hospital, Newcastle, United Kingdom; \#\#Klinikum Oldenburg, Oldenburg, Germany; ***Klinikum Nuernberg, Nuremberg, Germany; $\dagger \dagger$ Medizinische Universitaet Innsbruck, Austria; $\$+$ Ospedale

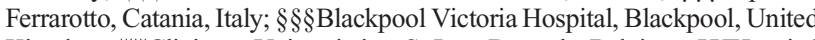

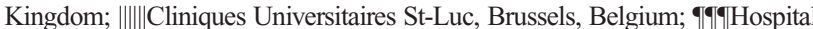
University Germans Trias I Pujol, Barcelona, Spain; \#\#\#Medizinischen Hochschule Hannover, Hannover, Germany; **** Mayo Clinic, Rochester, MN USA; $\uparrow \dagger \dagger$ Fondazione Poliambulanza, Brescia, Italy; and $+\$+\$$ University Medical Center Ljubljana, Ljubljana, Slovenia.

Support: There was no payment (fee, travel expenses, etc) to any of the participants from Sorin/LivaNova, Milan, Italy, Edwards Lifesciences, Corp, Irvine, CA USA, or Medtronic, Inc, Minneapolis, MN USA, except housing and catering that were supported by Sorin/LivaNova.

Disclosures: See next page.

Address correspondence and reprint requests to Mattia Glauber, MD, IRCCS Gruppo San Donato, Istituto Clinico Sant' Ambrogio, Via Faravelli, 16 , Milano 20149, Italy. E-mail: mattia.glauber@gmail.com.

Copyright (C) 2016 by the International Society for Minimally Invasive Cardiothoracic Surgery

This is an open-access article distributed under the terms of the Creative Commons Attribution-Non Commercial-No Derivatives License 4.0 (CCBY-NC-ND), where it is permissible to download and share the work provided it is properly cited. The work cannot be changed in any way or used commercially.

ISSN: 1556-9845/16/1103-0165
Methods: A panel of 28 international experts with expertise in both minimally invasive aortic valve replacement and rapid deployment valves was constituted. After thorough literature review, the experts rated evidence-based recommendations in a modified Delphi approach.

Results: No guideline could be retrieved. Thirty-three clinical trials and 9 systematic reviews could be identified for detailed text analysis to obtain a total of 24 recommendations. After rating by the experts 12 , final recommendations were identified: preoperative computed tomographic scan as well as intraoperative transesophageal echocardiography are highly recommended. Suitable annular sizes are 19 to $27 \mathrm{~mm}$. There is a contraindication for bicuspid valves only for type 0 and for annular abscess or destruction due to infective endocarditis. The use of sutureless and rapid deployment valves reduces extracorporeal circulation and aortic cross-clamp time and leads to less early complications as prolonged ventilation, blood transfusion, atrial fibrillation, pleural effusions, paravalvular leakages and aortic regurgitation, and renal replacement therapy, respectively. These clinical outcomes result in reduced intensive care unit and hospital stay and reduced costs. The use of sutureless and rapid deployment valves will lead to a higher adoption rate of minimally invasive approaches in aortic valve replacement. Respect should be taken to a necessary short learning curve for both sutureless and minimally invasive programs. Conclusions: Sutureless and rapid deployment aortic valve replacement together with minimally invasive approaches offers an attractive option in aortic valve placement for patients requiring biological valve replacement.

Key Words: Sutureless valves, Rapid deployment valves, Minimally invasive surgery, Aortic stenosis.

(Innovations 2016;11:165-173)

solated balloon valvuloplasty failed to mitigate the grave natural course of aortic valve stenosis with mortality rates of $70 \%$ at 1 year. ${ }^{1}$ Most patients with symptomatic aortic valve 


\begin{abstract}
Disclosures: Mattia Glauber, MD, is a consultant for Edwards Lifesciences, Corp, and serves on the speaker's bureau for Sorin/LivaNova. Simon C. Moten, MD, and Kevin H. T. Teoh, MD, are proctors for Sorin/LivaNova. Thierry A. Folliguet, MD, is a consultant for Sorin/LivaNova. Bart Meuris, MD, PhD, is a consultant for Sorin/LivaNova and Edwards Lifesciences, Corp. Peter J. Oberwalder, MD, is a proctor for Sorin/LivaNova. Gopal Bhatnagar, MD, is a consultant to Sorin/LivaNova. Michael A. Borger, MD, PhD, is a consultant to Edwards Lifesciences, Corp, Sorin/LivaNova, and Medtronic, Inc. Denis Bouchard, MD, receives proctor and lecture fees from Edwards Lifesciences Corp and Sorin/LivaNova. Olivier Bouchot, MD, is a consultant for Sorin/ LivaNova, Edwards Lifesciences Corp, and St. Jude Medical, Inc, St. Paul, MN USA. Otto E. Dapunt, MD, PhD, is a consultant for Sorin/LivaNova and Medtronic. Matteo Ferrarini, MD, is a proctor for Sorin/LivaNova. Theodor J. M. Fischlein, MD, is a consultant for Sorin/LivaNova. Guenther Laufer, MD, is a consultant for Edwards Lifesciences Corp. Carmelo Mignosa, MD, is a consultant for Sorin/LivaNova. Philippe Noirhomme, MD, is a proctor for Sorin/LivaNova. Steffen Pfeiffer, MD, is a consultant for Sorin/LivaNova. Xavier Ruyra-Baliarda, MD, receives royalties from OnX Technologies and Sorin/LivaNova; is a consultant for Cardiolink SL Spain, and St. Jude Medical Spain Group. Rakesh M. Suri, MD, DPhil, is a Clinical Screening Committee Member for Abbott, COAPT Trial; and National PI, Sorin Perceval Trial - reimbursed for related travel expenses. Giovanni Troise, MD, is a proctor for Sorin/ LivaNova. Borut Gersak, MD, PhD, is a consultant for Sorin/LivaNova. Eugenio Quaini, MD, Marco Solinas, MD, Antonio Miceli, MD, PhD, Manfredo Rambaldini, MD, Stephen C. Clark, FRCS (CTh), Russell Millner, MD, and Malakh Lal Shrestha, MBBS, PhD, declare no conflicts of interest.
\end{abstract}

stenosis therefore require replacement of the valve, ${ }^{2}$ currently most often facilitated by full median sternotomy representing the standard approach. With an increasing rate of elderly people due to demographic changes in western societies, risk profiles of patients requiring elective or urgent aortic valve replacement have subsequently changed. ${ }^{3}$ Transcatheter approaches have emerged in the last years for high-risk patients with the attempt to avoid both sternotomy and extracorporeal circulation as well as myocardial ischemia due to cross-clamping of the aorta. ${ }^{4}$ However, because the diseased valve is left in place and the current implant technique still has some limitations, the transcatheter aortic valve implantation (TAVI), both transapical and transfemoral, still carries few drawbacks such as paravalvular leakages, increased pacemaker rates, stroke, vascular complications, and reembolization. ${ }^{5}$ Furthermore, transapical TAVI remains a surgical procedure with similar surgical trauma as compared to minimally invasive approaches, ${ }^{6}$ whereas the crimping procedure with TAVI technology may even jeopardize the durability of the prosthesis. ${ }^{7}$ In order to provide a curative treatment to patients "in the grey zone" of medium to intermediate high risk ${ }^{8-10}$ and to fill the gap between TAVI and traditional AVR replacement, sutureless and rapid deployment valves have been introduced to facilitate safe and effective implantation of aortic biological valve prostheses in a rapid fashion using modern deployment techniques. ${ }^{11,12}$

To reduce the pitfalls of sternotomy in aortic valve replacement, minimally invasive approaches using either ministernotomy or right anterior minithoracotomy have been introduced, and safety and efficacy have been confirmed in a propensity score matched analysis ${ }^{13}$ and one review. ${ }^{14}$ However, owing to longer cross-clamp times and cardiopulmonary bypass times caused by the higher grade of complexity of the procedure, ${ }^{15}$ these approaches did not gain wide popularity, although even the use of various pericardial and porcine stentless valves proved to be possible through ministernotomy. ${ }^{16}$ Meanwhile, the Perceval Sutureless valve (Sorin/LivaNova Group, Saluggia, Italy), the EDWARDS INTUITY Elite (Edwards Lifesciences, Corp, Irvine, CA USA), and the Medtronic 3F Enable
Bioprosthesis (Medtronic, Inc, Minneapolis, MN USA) have proven their suitability for different minimally invasive approaches to reduce aortic cross-clamp time in a prospective, nonrandomized trial ${ }^{17}$ and one prospective randomized study, ${ }^{18}$ thus reducing perioperative risk of the patients in nonrandomized trials. ${ }^{19,20} \mathrm{~A}$ recent systematic review and meta-analysis on 12 studies using Perceval Sutureless valve, Medtronic 3F Enable, or EDWARDS INTUITY confirmed that sutureless aortic valve implantation is a safe procedure associated with shorter crossclamp and cardiopulmonary bypass time compared to conventional approaches. ${ }^{21}$ Sutureless and rapid deployment aortic valve replacement, furthermore, was associated with lower 30-day mortality and lower risk of postoperative aortic regurgitation compared to transapical TAVI in a multicenter, propensity-matched analysis ${ }^{22}$ and improved survival up to 24 months ${ }^{23}$ compared to TAVI, respectively. Compared to the implantation of stented valves, the use of Perceval sutureless valve in retrospective analyses resulted in shorter procedural times ${ }^{24}$ associated with better clinical outcomes as measured by blood transfusions, shorter intensive care unit stay, ventilation time, postoperative atrial fibrillation, pleural effusions, respectively, and reduced hospital costs by approximately $25 \%{ }^{25}$

Yet, no guidelines exist to define which patients might take profit from less invasive procedures in the therapy of aortic valve stenosis. The aim of the project was to gain evidence-based consensus on the use of sutureless and rapid deployment valves in minimally invasive isolated aortic valve replacement, and to define the role of minimally invasive aortic valve replacement with sutureless and rapid deployment valves.

\section{METHODS}

Three approved sutureless and rapid deployment valves with specific features of design and implantation technique were included in the literature search and the panel process.

\section{Perceval Sutureless Valve}

The Perceval sutureless valve (Fig. 1) represents a truly sutureless aortic valve prosthesis. It comprises a biological component of bovine pericardium treated to reduce the risk of calcification, and a self-expanding and elastic nitinol alloy stent, covered by a thin coating of carbofilm for improved biocompatibility. The stent consists of 2 rings, as well as 9 connecting struts, with the dual task of supporting the valve and holding it in place with no need for any permanent suture. The stent adapts to the anatomy of the aorta and follows its movements, relieving the stress on the leaflets and enhancing valve durability. For implantation, the valve is collapsed with an atraumatic device compression, assuring that the valve leaflets are not affected. Perceval is lowered until the correct position while collapsed, enhancing direct visualization, and then self-expands back to its original diameter. Ballooning is recommended by the manufacturer to optimize adherence to the native aortic wall.

\section{EDWARDS INTUITY}

The EDWARDS INTUITY Elite valve (Fig. 2) is a stented trileaflet bovine pericardial bioprosthesis with a balloon-expandable cloth-covered skirt frame at the inflow aspect representing rapid deployment valve prosthesis. For implantation, 3 equidistant figure-of-eight or mattress guiding sutures are 


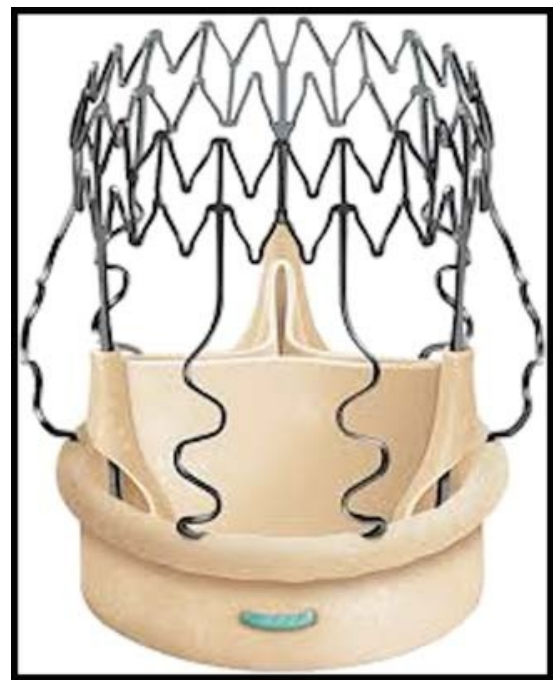

FIGURE 1. Perceval sutureless valve. Reprinted from Barnhart et al. Current clinical evidence on rapid deployment aortic valve replacement: sutureless aortic bioprostheses. Innovations. 2016;11:7-14.

placed through the annulus at the nadir of each sinus and then passed through the corresponding black marks on the nadir portion of the valve suture ring. The valve is positioned into the aortic annulus by use of the guide sutures and 3 tourniquets, with the stent and polyester sealing cloth being seated directly below the aortic annulus. A thoracoscope can be occasionally inserted through the holding device to confirm proper positioning. Once the valve is properly seated, the balloon-expandable frame is deployed with short balloon inflation. The guiding sutures are finally tied.

\section{Medtronic 3F Enable Bioprosthesis}

The 3 f Enable Model 6000 valve (Fig. 3) as another rapid deployment valve prosthesis is made with a stentless valve of 3 equal sections of equine pericardial tissue sewn in a selfexpanding nitinol support frame. The nitinol frame is intended to maintain the tissue valve geometry, optimize its flow area, and

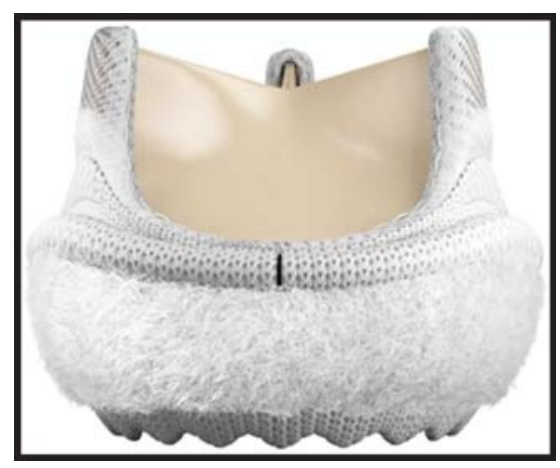

FIGURE 2. EDWARDS INTUITY. Reprinted from Barnhart et al. Current clinical evidence on rapid deployment aortic valve replacement: sutureless aortic bioprostheses. Innovations. 2016;11:7-14.

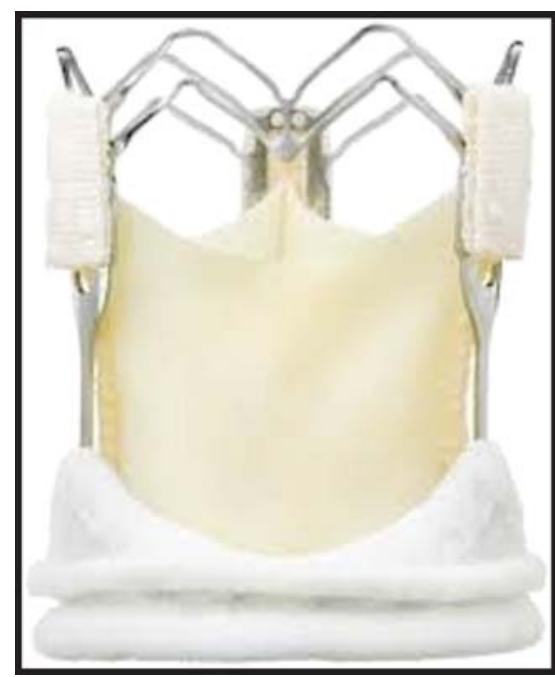

FIGURE 3. Medtronic 3F Enable bioprosthesis. Reprinted from Barnhart et al. Current clinical evidence on rapid deployment aortic valve replacement: sutureless aortic bioprostheses. Innovations. 2016;11:7-14.

eliminate the potential for misplaced attachment of the commissural tabs. The properties of nitinol and the flexibility of the equine pericardial leaflets allow the device to be folded in chilled water and positioned appropriately within minutes intraoperatively. On deployment, its shape and size return to the preset dimensions and the outward radial forces keep the valve fixed at the target position. For implantation, a single guiding suture was recommended to support placement of the valve at the level of the annulus. The polyester flange at the inflow aspect promotes tissue ingrowth, thus contributing to the long-term stabilization of the valve. However, after some cases of migration, the company is now recommending to use 2 permanent sutures.

\section{Literature Search Strategy and Selection Criteria}

Literature search was performed from April to November 2014. To be eligible for the review, studies should evaluate the use of sutureless or rapid deployment valves in isolated aortic valve replacement facilitated by minimally invasive approaches. Articles were identified via an electronic search on PubMed, Embase, and Cochrane Library. We used the following keywords: "aortic valve replacement" and "minimally invasive" and "sutureless" or "rapid deployment" in our search. We also performed manual search for the articles in the reference. We only searched studies that were published in English. Abstracts and unpublished studies were excluded. If the author reported results that were obtained on the same patient population in several studies, we would use the most recent or complete study. Besides clinical studies, relevant guidelines published since 2006, with their latest version if they had undergone substantial revision, were included.

Two independent scientists performed a full-text analysis with the emphasis on selection of main topics to represent possible recommendations on the use of minimally invasive approaches in isolated aortic valve replacement in general and 
the indications, benefits, possible pitfalls, contraindications, perioperative conditions, complications and their treatment, outcome and follow-up criteria for the use of sutureless and rapid deployment valves in minimally invasive approaches. These selected main topics represented the basic material for the first round of the Delphi process.

\section{Panel of Experts}

The selection of panel experts should reflect the population of cardiac surgeons involved both in minimally invasive aortic valve replacement and the use of sutureless and rapid deployment valves for use in aortic position. For this purpose, a "snowball sampling" approach was used, starting with a preliminary list of possible experts, defined by credibility to the target audience of cardiac surgeons considering the use of sutureless valves and rapid deployment valves in aortic valve replacement. A steering committee (M.G., T.A.F., B.M., T.F.M.F., and B.G.) identified and rated possible candidates according to the following criteria. Possible credibility was defined by recent activities on the mentioned topics by (1) publication of scientific papers (studies, reviews) with frequent citations, (2) playing an active role in guidelines committees, and (3) representing speaker on recent congresses of relevant scientific societies, respectively. Additional possible experts were included to the preliminary list if recommended by one of the final experts.

From the preliminary list, experts were contacted for further participation according to their current clinical expertise. Only experts with an experience of at least 100 cases undergoing minimally invasive aortic valve replacement (excluding all cases of transfemoral or transapical aortic valve implantation) and at least 50 of the minimally invasive cases using sutureless or rapid deployment aortic valve prostheses were chosen. All experts had to declare any conflicts of interest before final constitution of the panel.

Outcomes had to be reported according to the recommendations of the American Association for Thoracic Surgery, The Society of Thoracic Surgeons, the European Association for Cardio-Thoracic Surgery, ${ }^{26}$ and the Valve Academic Research Consortium. ${ }^{27}$

\section{Panel Process}

After selection of experts, in a first round they were asked to rate the main topics to be included in the consensus selected from literature review. Experts were asked to discard or add topics not represented yet and to give further details on each main topic to prepare panel discussion during second round. First round was performed from July to September 2014 electronically. Main topics were included if mentioned to be relevant by at least one of the experts and excluded if discarded by all experts. The second round represented a meeting of the expert panel which took place October 10, 2014. Each main topic that was rated as relevant during first round, was presented with evidence based recommendations and major clinical results if published, and then intensively discussed with regard to their eligibility as general recommendations for cardiac surgeons to give decision criteria for the use of sutureless and rapid deployment valves in isolated aortic valve replacement. A writing committee prepared the recommendations for final discussion through a third electronic round including literature and evidence screening, and finally wrote the manuscript.

\section{RESULTS}

\section{Literature Search}

The search model could retrieve a total of 6,025 publications covering a wide range of medical fields. After title and abstract screening and final full text analysis a total of 43 papers covering 33 clinical trials and 9 systematic reviews were identified (Table 1). However, no guidelines on the use of sutureless and rapid deployment valves in minimally invasive aortic valve replacement could be identified as presumed. Additional 25 papers describing the results of clinical studies were included from hand search resulting a total of 68 papers to be included.

\section{Results of Delphi Panel and Expert Panel Discussion}

A total of 28 international experts fulfilling the criteria of at least 100 cases using minimally invasive approaches for aortic valve replacement, in particular minithoracotomy and partial sternotomy, and at least 50 of these minimally invasive cases using sutureless or rapid deployment aortic valve prostheses were selected during selection process to take part in all panel rounds. After the first round a total of 24 possible main topics were prepared for the discussion during the second panel round. After discussion and final electronical round, the experts identified a total of 12 recommendations for the use of sutureless and rapid deployment valves in minimally aortic valve replacement were identified by the experts (Table 2).

\section{DISCUSSION}

The experts identified a variety of benefits for the use of sutureless and rapid deployment valves in case of aortic valve replacement as compared to pericardial, stented, and stentless valves using conventional surgical approaches, and transfemoral and transapical TAVI, respectively. Additionally, a number of benefits compared to stented biological valves using minimally invasive approaches could be identified, which is the main focus of this paper and of this panel with expertise on minimally invasive procedures.

A recent meta-analysis ${ }^{21}$ has shown how observational evidence suggests that sutureless aortic valve implantation is not only a safe procedure associated with shorter cross-clamp

TABLE 1. Results of Literature Search

\begin{tabular}{lcccc}
\hline & $\begin{array}{c}\text { Clinical } \\
\text { Trials }\end{array}$ & Guidelines & $\begin{array}{c}\text { Systematic } \\
\text { Review }\end{array}$ & All \\
\hline Search terms & & & & \\
- Aortic valve replacement (A) & 991 & 18 & 16 & 1,025 \\
- Minimally invasive (B) & 3,213 & 91 & 1,488 & 4,792 \\
- Sutureless (C) & 141 & - & 19 & 160 \\
- Rapid deployment (D) & 27 & - & 21 & 48 \\
Total & 4,372 & 109 & 1,544 & 6,025 \\
Search model & & & & \\
- Terms A and B and (C or D) & 33 & - & 9 & 43 \\
\hline
\end{tabular}


TABLE 2. Recommendations of Experts for the Implantation of Sutureless and Rapid Deployment Valves in Minimally Invasive Aortic Valve Replacement After Second Round of the Panel Process

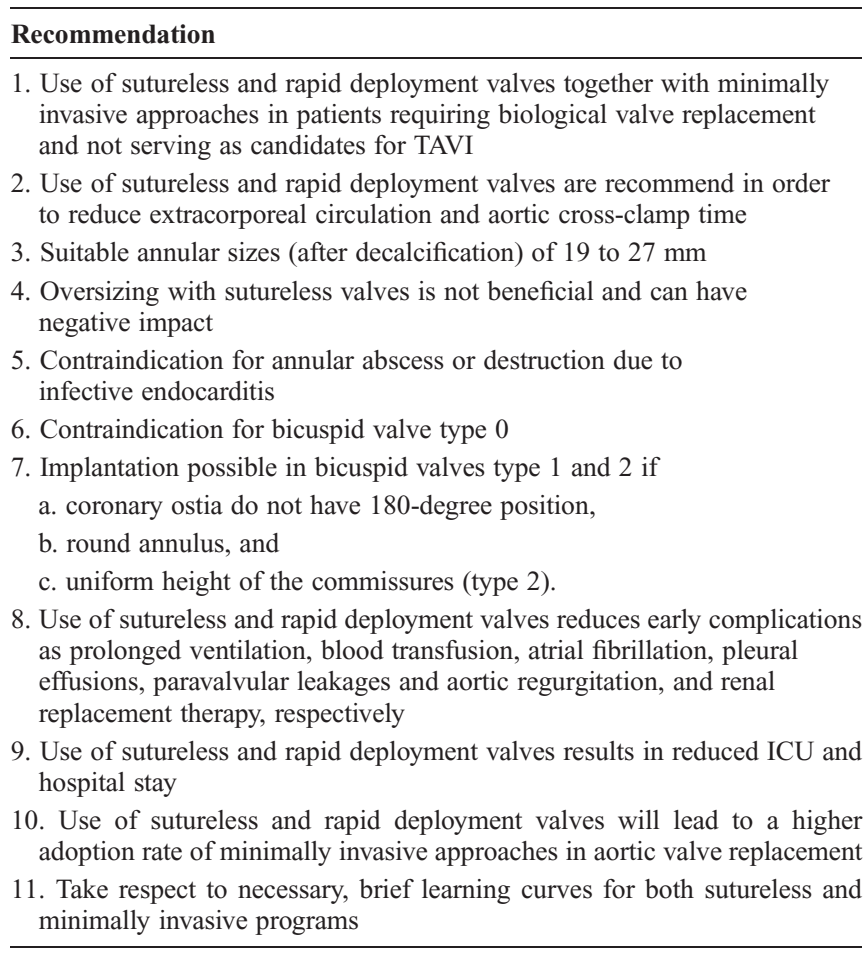

and CPB duration, and comparable complication rates to the conventional approaches, but also facilitates minimally invasive approaches.

\section{Diagnostics and Patient Selection}

The indication and contraindication for sutureless and rapid deployment valves first of all follow the general recommendations for the choice of biological stented prostheses in aortic valve replacement, according to the current guidelines. ${ }^{2,28}$ Since current recommendations focus on patients at an age of 65 years or older to be candidates for biological valve replacement, the experts also recommend to consider sutureless and rapid deployment valves for patients older than 65 years.

The experts identified a high standard of preoperative imaging as a central precondition for proper patient selection and procedure planning, which should be applied the same way as for TAVI procedures. Therefore, a computed tomographic (CT) scan providing sufficient resolution with expertise in the interpretation is recommended besides the classical diagnostics as transthoracic echocardiography and coronary angiography used to verify the indication, and exclude patients with additional cardiac pathologies requiring a different surgical approach. This way the ascending aorta can be displayed, and a proper planning of aortotomy with respect to annular diameter can be performed, as well as a proper size estimate and a closer analysis of the extent of calcification of the ascending aorta. ${ }^{29}$ Additionally, the CT scan is useful for the location of coronary ostia, the definition of the aortic root geometry, especially with respect to the relation between aortic annulus and sinotubular junction, for the identification of the type of bicuspid valve, if present, and for the positioning of the aortic root in relation to the sternum and the second right intercostal space. In case of renal failure or allergies to contrast media, native CT scan ${ }^{30}$ or reduced dosage of contrast media ${ }^{31}$ may be sufficient for most scenarios. The location of calcifications in the aortic root wall may affect the choice of the sutureless prosthesis, since, for instance, the Edwards Intuity requires a hockey stick incision that goes deep to the noncoronary sinus. ${ }^{32}$

The experts identified annulus sizes of less than $19 \mathrm{~mm}$ as too small for the implantation of sutureless and rapid deployment valves, since owing to size limits of the current available prostheses, annulus enlargement procedures would be necessary. Those procedures can be done using most minimally invasive approaches, thanks to full access to the aortic root and subvalvular structures. ${ }^{33}$ However, since these procedures may be time consuming and the implantation of patch material in the aortic annulus may result in less stability to anchor a selfexpanding valve, root enlargement procedures should be avoided if sutureless or rapid deployment valves are considered. On the other hand, since available prostheses are limited to an annular size of $27 \mathrm{~mm}$ and since no suture material on the annular level might reduce annulus size, the use of sutureless and rapid deployment valves currently is limited to annular sizes of 19 to $27 \mathrm{~mm}$. Since multislice CT may overestimate the annulus diameter, 3-dimensional transesophageal echocardiography may help for preprocedural evaluation. ${ }^{34}$ However, even with preoperative CT scan, additional intraoperative sizing is necessary after thorough resection of the native calcified aortic valve and decalcification of the aortic annulus. In case of degenerative aortic regurgitation with annuloaortic ectasia, the experts recommend not to use a sutureless or rapid deployment valve to prevent valve migration.

Bicuspid valves are contraindicated if no raphe (type 0 according to Sievers et $\mathrm{al}^{35}$ ) is present; in case of type 1 bicuspid valve with one raphe, sutureless and rapid deployment valves can be used if coronary ostia are not in a 180-degree position and the annulus is circular after decalcification; likewise, type 2 bicuspid valve with 2 raphes are indicated if the 2 commissures have approximately the same height.

Since only case reports describe the potential use of sutureless and rapid deployment valves and according to the recommendations of current guidelines ${ }^{2,28}$ the panel experts do not recommend the use of sutureless valves in extensive endocarditis with annular abscess or destruction since usually defects in the aortic root or annulus remain even after proper debridement of the infected structures.

To verify proper systolic and diastolic function of the implanted valve and to verify left ventricular wall motility reflecting unchanged coronary perfusion, intraoperative transesophageal echocardiography (TEE) is useful in all cases of sutureless and rapid deployment valves irrespective of the personal experience and the surgical approach, also according to the current recommendations for TAVI. ${ }^{36}$ Transesophageal echocardiography should be started before induction of cardiopulmonary bypass with documentation of valve pathology, ventricular function, and associated valve pathologies and must be performed both 
during weaning from cardiopulmonary bypass and at the end of the operation. ${ }^{37}$

\section{Surgical Approach and Valve Prosthesis Selection}

The first reports on minimally invasive aortic valve replacement have been published almost 20 years ago by different groups, using upper or right-sided partial sternotomy ${ }^{33,38}$ or parasternal minithoracotomy, ${ }^{39}$ respectively. The primary aim was to avoid full sternotomy to reduce surgical trauma, improve patient comfort, and reduce postoperative ICU and hospital stay to lower costs in a retrospective study. ${ }^{40}$ However, in contrast to minimally invasive coronary artery bypass grafting, which was also introduced to avoid extracorporeal circulation, the main benefit of minimally invasive approaches in cardiac valve surgery remained in less pain and thus improved patient comfort, ${ }^{41}$ postoperative ventilation time, ${ }^{42,43}$ and a significant reduction of blood transfusion requirements ${ }^{44}$ in 2 propensity score-matching studies and 1 meta-analysis. A series of 1,639 patients over 16 years could demonstrate benefits, especially for patients undergoing reoperations and for those older than 80 years. ${ }^{42}$ Despite these benefits, partial sternotomy and parasternal thoracotomy as approach for aortic valve replacement did not reach wide popularity owing to concerns on limited access.

However, the experience with central cannulation via minimally invasive approaches both in aortic and mitral valve surgery facilitated other minimally invasive approaches as right minithoracotomy, for example, in the second intercostal space, with optimal exposure of the aortic root and annulus ${ }^{45}$ The use of pericardial stentless valves for subcoronary implantation technique was shown to be possible via partial sternotomy. ${ }^{16}$ Compared to full sternotomy, the right anterior thoracotomy could prove lower incidence of postoperative atrial fibrillation and blood transfusion, and shorter ventilation time and hospital length of stay in nonrandomized but propensity score-matched trials. ${ }^{13,46}$ Even in case of prior median sternotomy, the right minithoracotomy as approach for redo aortic valve replacement could show benefits with regard to shorter ICU and total hospital stays, along with lower morbidity, and a trend toward lower mortality in retrospective analysis. ${ }^{47}$ Additionally, compared to ministernotomy, right minithoracotomy featured benefits in retrospective analyses with regard to lower postoperative complication rates, shorter hospital stay ${ }^{48}$ and hospital costs, ${ }^{49}$ respectively.

As a next step, the successful use of sutureless valves could be demonstrated via partial sternotomy in a nonrandomized multicenter study ${ }^{50}$ and with even better surgical access via right anterior minithoracotomy. ${ }^{51}$ The latter approach serves as an alternative for high-risk patients to facilitate full decalcification of the aortic annulus. ${ }^{52}$ Excellent hemodynamic results, postoperative outcome, and 1-year survival of $90 \%$ were recently demonstrated. ${ }^{20}$ A recent propensity-matched analysis could also show the advantage of standard diseased valve removal with shorter procedural times, resulting in the recommendation that minimally invasive sutureless aortic valve replacement may be the first-line treatment even for high-risk patients considered in the "gray zoner" between TAVI and conventional surgery. ${ }^{8}$

All the experts highly recommend the use of sutureless and rapid deployment valves together with minimally invasive approaches for isolated aortic valve replacement in patients requiring biological valve replacement, which are not candidates for transfemoral or transapical TAVI according to the current guidelines.

However, a specific learning curve is necessary for all sutureless valves, regardless of the prosthesis model ${ }^{53,54}$ and the minimally invasive approach. ${ }^{55-57}$ Therefore, the experts recommend proper education and proctoring by experienced surgeons for the introduction of both programs to avoid complications.

There is no recommendation on the use of specific sutureless or rapid deployment valves; however, the experts identified specific conditions of the current available rapid deployment valve prostheses with respect to the aortotomy and possible impact on the selection of the surgical approach during the second round of the panel process, which might be taken into consideration when planning the procedures. All the sutureless and rapid deployment valve prostheses are designed to target a less traumatic procedure with regard to aortic root structures.

The EDWARDS INTUITY Elite has the advantage to require an aortotomy close to the annulus in the noncoronary sinus; this facilitates better access and decalcification of the annulus, but it is not collapsible.

The Perceval Sutureless valve requires a bit higher aortotomy but can be fully collapsed for implantation for atraumatic insertion.

The Medtronic 3F Enable Bioprosthesis, owing to its higher profile, requires a much higher aortotomy but is foldable for its implantation for atraumatic insertion.

\section{Extracorporeal Circulation and Cross-clamp Time}

Most concepts in aortic valve replacement, which includes resection of diseased valves and decalcification of the aortic annulus, use extracorporeal circulation, aortic cross-clamping, and myocardial protection. Compared to transfemoral and transapical TAVI, the main benefits of sutureless valves can be found in creating a round, smooth annulus to safely fix a valve prosthesis with maximal orifice area, almost without the risk of paravalvular leakage, migration, or damage to conduction system and coronary ostia. However, these mostly conventional approaches carry the well-known risks of myocardial infarction due to insufficient myocardial protection, and systemic inflammatory response syndrome due to the extracorporeal circulation system. Reduced cross-clamp and extracorporeal circulation times may lower both risks. ${ }^{57}$ Sutureless and rapid deployment valves carry the potential to shorten cross-clamp time, resulting in significantly shorter procedural times compared to standard conventional valve prostheses in both conventional and minimal invasive ${ }^{24,25}$ surgical approaches. The experts therefore recommend the use of sutureless and rapid deployment valves in each case, with the necessity to reduce extracorporeal circulation and aortic cross-clamp times.

\section{Postoperative Course}

The experts found evidence for reduced ICU and hospital stay ${ }^{25}$ after the use of sutureless valves from different propensity-matched score analyses compared to standard conventional aortic valve prostheses or TAVI. ${ }^{52}$ Since postoperative complications contribute to prolongation of both ICU and hospital stay, the experts identified reduced ventilation times, ${ }^{19,25}$ reduced blood transfusion rates, and lower incidence of atrial fibrillation 
and pleura effusions, ${ }^{25}$ as possible reasons for improved overall outcome. Transcatheter aortic valve implantation patients showed paravalvular leakages more frequently than sutureless and rapid deployment valves ${ }^{8}$; recent studies, however, suggest a decrease of transvalvular regurgitation ${ }^{58}$ and paravalvular leakages ${ }^{59}$ with modified design. Multivariate analysis showed sutureless aortic valve replacement to have a not statistically significant protective effect against aortic regurgitation, pacemaker implantation, and renal replacement therapy as compared with transapical TAVI ${ }^{60} \mathrm{~A}$ multicenter study with retrospective analysis of 314 patients demonstrated 1-year survival of $90.5 \%$, and freedom from valverelated mortality, stroke, endocarditis, and reoperation of $99.0 \%$, $98.1 \%, 99.2 \%$, and $98.3 \%$, respectively. ${ }^{61}$ At a $24-$ month follow-up, overall survival free from major adverse cardiac and cerebrovascular events and prosthetic regurgitation was significantly better $(P<0.05)$ after sutureless valve implantation $(91.6 \% \pm 3.8 \%, \mathrm{n}=53)$ than after TAVI $(70.5 \pm 7.6 \%, \mathrm{n}=55) .^{23}$ Owing to the lack of long-term studies for sutureless and fast deployment valves with innovative stent designs, no recommendation for late outcome with respect to valve durability may be given, but the current results are promising. So far, 5-year results of the Medtronic 3F Enable bioprosthesis and of the Perceval sutureless valve showed excellent results in hemodynamics and freedom from structural valve deterioration. For Medtronic 3F Enable bioprosthesis in 141 patients at 5 years ${ }^{62}$ and for Perceval in a cohort of more than 700 patients with 5 years of follow-up coming from 3 consecutive clinical trials recently presented by Prof. Shrestha during EACTS 2014, freedom from structural valve deterioration reported was $100 \%$. The longest published follow-up for the Edwards Intuity valve is of 3 years, in a cohort of 287 patients, ${ }^{63}$ with no cases of structural valve deteriorations reported.

However, there is no proof for any effect of minimally aortic valve surgery on durability. The experts recommend the use of sutureless and rapid deployment valves in order to reduce perioperative and medium term morbidity. Owing to reduced morbidity, also postoperative ICU and total hospital stay may be reduced.

The experts found no evidence and could therefore give no recommendation for the effect of sutureless and rapid deployment valves in minimally invasive surgery with regard to overall mortality, prosthetic valve endocarditis, or other hospital-acquired infections. Reduced wound infections, especially the complete avoidance of deep sternal wound infections, and reduced rate of mediastinitis are apparently linked to the approach of right anterior minithoracotomy and not to the use of sutureless valves.

\section{CONCLUSIONS}

In conclusion, sutureless and rapid deployment valves overcome most of the previous limitations in minimally aortic valve replacement, in particular, prolonged cross-clamp times, owing to limited access in partial sternotomy. Sutureless and rapid deployment valves by their design deliver comparable hemodynamic results as stentless valves. Starting a program for approaching minimally invasive aortic valve replacement should as a first step include partial sternotomy and then, after reaching sufficient individual and institutional expertise, include right anterior minithoracotomy. With a short learning curve, which has to be taken into account when starting a program in this stepwise fashion, the implantation of sutureless valves via a minimally invasive approach is an easy and safe procedure. Reducing cross-clamp times and enabling the implantation via limited access the use of sutureless and rapid deployment valves overcomes most of the previous limitations in minimally invasive aortic valve replacement. In the future, this will result in a higher adoption rate of minimally invasive techniques for many surgeons, leading to more patient comfort, shortening of hospital stay, and even reduction of costs depending on the reimbursement system. Additionally, by using sutureless aortic valves, the individual surgeon's skills do not represent as critical factors for the safety and efficacy in minimally invasive aortic valve replacement. The international experts recommend sutureless aortic valve replacement together with minimally invasive approaches for eligible patients requiring biological valve replacement.

\section{REFERENCES}

1. Leon MB, Smith CR, Mack M, et al. Transcatheter aortic-valve implantation for aortic stenosis in patients who cannot undergo surgery. $N$ Engl J Med. 2010;363:1597-1607.

2. Vahanian A, Alfieri O, Andreotti F, et al. Guidelines on the management of valvular heart disease (version 2012): the Joint Task Force on the Management of Valvular Heart Disease of the European Society of Cardiology (ESC) and the European Association for Cardio-Thoracic Surgery (EACTS). Eur J Cardiothorac Surg. 2012;42:S1-S44.

3. Brown $\mathrm{J}, \mathrm{O}^{`} B$ rien $\mathrm{SM}, \mathrm{Wu} \mathrm{C}$, et al. Isolated aortic valve replacement in North America comprising 108,687 patients in 10 years: changes in risks, valve types and outcomes in the Society of Thoracic Surgeons National Database. J Thorac Cardiovasc Surg. 2009;137:82-90.

4. Reynolds MR, Magnuson EA, Wang K, et al. Health-related quality of life after transcatheter or surgical aortic valve replacement in high-risk patients with severe aortic stenosis: results from the PARTNER (Placement of AoRTic TraNscathetER Valve) Trial (Cohort A). J Am Coll Cardiol. 2012;60:548-558.

5. Zahn R, Gerckens U, Grube E, et al. Transcatheter aortic valve implantation: first results from a multi-centre real-world registry. Eur Heart J. 2011;32:198-204.

6. Walther T, Schuler G, Borger MA, et al. Is transapical aortic valve implantation really less invasive than minimally invasive aortic valve replacement? Eur Heart J. 2010;31:1398-1403.

7. Kiefer P, Gruenwald F, Kempfert J, et al. Crimping may affect the durability of transcatheter valves: an experimental analysis. Ann Thorac Surg. 2011;92:155-160.

8. Santarpino G, Pfeiffer S, Jessl J, et al. Sutureless replacement versus transcatheter valve implantation in aortic valve stenosis: a propensitymatched analysis of 2 strategies in high-risk patients. $J$ Thorac Cardiovasc Surg. 2014;147:561-567.

9. Onorati F, D'Errigo P, Barbanti M, et al. Different impact of sex on baseline characteristics and major periprocedural outcomes of transcatheter and surgical aortic valve interventions: results of the multicenter Italian OBSERVANT Registry. J Thorac Cardiovasc Surg. 2014;147:1529-1539.

10. Giordana F, D'Ascenzo F, Nijhoff F, et al. Meta-analysis of predictors of allcause mortality after transcatheter aortic valve implantation. Am J Cardiol. 2014;114:1447-1455.

11. Folliguet TA, Laborde F, Zannis K, et al. Sutureless Perceval aortic valve replacement: results of two European centers. Ann Thorac Surg. 2012; 93:1483-1488.

12. Martens S, Ploss A, Sirat S, et al. Sutureless aortic valve replacement with the $3 \mathrm{f}$ Enable aortic bioprosthesis. Ann Thorac Surg. 2009;87:1914-1917.

13. Glauber M, Miceli A, Gilmanov D, et al. Right anterior minithoracotomy versus conventional aortic valve replacement: a propensity score matched study. J Thorac Cardiovasc Surg. 2013;145:1222-1226. 
14. Brown ML, McKellar SH, Sundt TM, Schaff HV. Ministernotomy versus conventional sternotomy for aortic valve replacement: a systematic review and meta-analysis. J Thorac Cardiovasc Surg. 2009;137:670-679.

15. Foghsgaard S, Schmidt TA, Kjaergard HK. Minimally invasive aortic valve replacement: late conversion to full sternotomy doubles operative time. Tex Heart Inst J. 2009;36:293-297.

16. Karimov JH, Cerillo AG, Gasbarri T, Solinas M, Bevilacqua S, Glauber M. Stentless aortic valve implantation through an upper manubriumlimited V-type ministernotomy. Innovations. 2010;5:378-380.

17. Kocher AA, Laufer G, Haverich A, et al. One-year outcomes of the Surgical Treatment of Aortic Stenosis With a Next Generation Surgical Aortic Valve (TRITON) trial: a prospective multicenter study of rapid-deployment aortic valve replacement with the EDWARDS INTUITY Valve System. J Thorac Cardiovasc Surg. 2013;145:110-115.

18. Borger MA, Moustafine V, Conradi L, et al. A randomized multicenter trial of minimally invasive rapid deployment versus conventional full sternotomy aortic valve replacement. Ann Thorac Surg 2015;99:17-25.

19. Gilmanov D, Miceli A, Ferrarini M, et al. Aortic valve replacement through right anterior minithoracotomy: can sutureless technology improve clinical outcomes? Ann Thorac Surg. 2014;98:1585-1592.

20. Miceli A, Santarpino G, Pfeiffer S, et al. Minimally invasive aortic valve replacement with Perceval S sutureless valve: early outcomes and one-year survival from two European centers. J Thorac Cardiovasc Surg. 2014;148: 2838-2843.

21. Phan K, Tsai YC, Niranjan N, et al. Sutureless aortic valve replacement: a systematic review and meta-analysis. Ann Cardiothorac Surg. 2015;4: $100-111$.

22. D’Onofrio A, Rizzoli G, Messina A, et al. Conventional surgery, sutureless valves, and transapical aortic valve replacement: what is the best option for patients with aortic valve stenosis? A multicenter, propensity-matched analysis. J Thorac Cardiovasc Surg. 2013;146:1065-1070.

23. Muneretto C, Bisleri G, Moggi A, et al. Treating the patients in the 'greyzone' with aortic valve disease: a comparison among conventional surgery, sutureless valves and transcatheter aortic valve replacement. Interact Cardiovasc Thorac Surg. 2015;20:90-95.

24. Koenig KC, Wahlers T, Scherner M, et al. Sutureless Perceval aortic valve in comparison with the stented Carpentier-Edwards Perimount aortic valve. J Heart Valve Dis. 2014;23:253-258.

25. Pollari F, Santarpino G, Dell'Aquila AM, et al. Better short-term outcome by using sutureless valves: a propensity-matched score analysis. Ann Thorac Surg. 2014;98:611-616.

26. Akins CW, Miller DC, Turina MI, et al. Guidelines for reporting mortality and morbidity after cardiac valve interventions. J Thorac Cardiovasc Surg. 2008; 135:732-738.

27. Kappetein AP, Head SJ, Généreux P, et al. Updated standardized endpoint definitions for transcatheter aortic valve implantation: the Valve Academic Research Consortium-2 consensus document. J Thorac Cardiovasc Surg. 2013;145:6-23.

28. Nishimura RA, Otto CM, Bonow RO, et al. 2014 AHA/ACC guideline for the management of patients with valvular heart disease: a report of the American College of Cardiology/American Heart Association Task Force on Practice Guidelines. J Thorac Cardiovasc Surg. 2014;148:e1-e132.

29. Lehmkuhl L, Foldyna B, Haensig M, et al. Role of preprocedural computed tomography in transcatheter aortic valve implantation. Rofo. 2013;185: 941-949.

30. Jochheim D, Schneider VS, Schwarz F, et al. Contrast-induced acute kidney injury after computed tomography prior to transcatheter aortic valve implantation. Clin Radiol. 2014;69:1034-1038.

31. Azzalini L, Abbara S, Ghoshhajra BB. Ultra-low contrast computed tomographic angiography (CTA) with $20-\mathrm{mL}$ total dose for transcatheter aortic valve implantation (TAVI) planning. J Comput Assist Tomogr. 2014;38:105-109.

32. Borger MA, Dohmen P, Misfeld M, Mohr FW. Minimal invasive implantation of an EDWARDS INTUITY rapid deployment aortic valve. Multimed Man Cardiothorac Surg. 2013;2013:mmt011.

33. Gundry SR, Shattuck OH, Razzouk AJ, et al. Facile minimally invasive cardiac surgery via ministernotomy. Ann Thorac Surg. 1998;65: $1100-1104$.
34. Husser O, Holzamer A, Resch M, et al. Prosthesis sizing for transcatheter aortic valve implantation - comparison of three dimensional transesophageal echocardiography with multislice computed tomography. Int $J$ Cardiol. 2013;168:3431-3438.

35. Sievers HH, Schmidtke C. A classification system for the bicuspid aortic valve from 304 surgical specimens. $J$ Thorac Cardiovasc Surg. 2007;133: $1226-1233$.

36. Bilen E, Sari C, Durmaz T, et al. The importance of echocardiography in transcatheter aortic valve implantation. Echocardiography. 2014;31: 101-110.

37. Ramakrishna H, Kohl BA, Jassar AS, et al. Incidental moderate mitral regurgitation in patients undergoing aortic valve replacement for aortic stenosis: review of guidelines and current evidence. $J$ Cardiothorac Vasc Anesth. 2014;28:417-422.

38. Benetti FJ, Mariani MA, Rizzardi JL, et al. Minimally invasive aortic valve replacement. J Thorac Cardiovasc Surg. 1997;113:806-807.

39. Minale C, Reifschneider HJ, Schmitz E, et al. Early results of minimally invasive aortic valve replacement. Experience with the first 34 cases. G Ital Cardiol. 1997;27:458-461.

40. Cohn LH, Adams DH, Couper GS, et al. Minimally invasive cardiac valve surgery improves patient satisfaction while reducing costs of cardiac valve replacement and repair. Ann Surg. 1997;226:421-426.

41. Bang JH, Kim JW, Lee JW, et al. Minimally invasive approaches versus conventional sternotomy for aortic valve replacement: a propensity score matching study. Korean J Thorac Cardiovasc Surg. 2012;45: $80-84$.

42. Brinkman WT, Hoffman W, Dewey TM, Sutherland FW. Aortic valve replacement surgery: comparison of outcomes in matched sternotomy and PORT ACCESS groups. Ann Thorac Surg. 2010;90:131-135.

43. Khoshbin E, Prayaga S, Kinsella J, Sutherland FW. Mini-sternotomy for aortic valve replacement reduces the length of stay in the cardiac intensive care unit: meta-analysis of randomised controlled trials. BMJ Open. 2011;1:e00266.

44. Korach A, Shemin RJ, Hunter CT, et al. Minimally invasive versus conventional aortic valve replacement: a 10-year experience. J Cardiovasc Surg (Torino). 2010;51:417-421.

45. Glauber M, Farneti A, Solinas M, Karimov J. Aortic valve replacement through a right minithoracotomy. Multimed Man Cardiothorac Surg. 2006;2006:mmcts.2005.001826.

46. Gilmanov D, Bevilacqua S, Murzi M, et al. Minimally invasive and conventional aortic valve replacement: a propensity score analysis. Ann Thorac Surg. 2013;96:837-843.

47. Pineda AM, Santana O, Reyna J, et al. Outcomes of reoperative aortic valve replacement via right mini-thoracotomy versus median sternotomy. J Heart Valve Dis. 2013;22:50-55.

48. Miceli A, Murzi M, Gilmanov D, et al. Minimally invasive aortic valve replacement using right minithoracotomy is associated with better outcomes than ministernotomy. $J$ Thorac Cardiovasc Surg. 2014;148:133-137.

49. Rodriguez E, Malaisrie SC, Mehall JR, et al. Right anterior thoracotomy aortic valve replacement is associated with less cost than sternotomy-based approaches: a multi-institution analysis of 'real world' data. J Med Econ. 2014;19:1-7.

50. Dalén M, Biancari F, Rubino AS, et al. Ministernotomy versus full sternotomy aortic valve replacement with the sutureless Perceval bioprosthesis: a multicenter study. Ann Thorac Surg. 2015;99:524-530.

51. Cerillo AG, Bevilacqua S, Farneti PA, et al. Sutureless aortic valve replacement through a right minithoracotomy. J Heart Valve Dis. 2012;21:168-171.

52. Santarpino G, Pfeiffer S, Vogt F, et al. Advanced age per se should not be an exclusion criterion for minimally invasive aortic valve replacement. $J$ Heart Valve Dis. 2013;22:455-459.

53. Santarpino G, Pfeiffer $\mathrm{S}$, Concistrè G, et al. A supra-annular malposition of the Perceval S sutureless aortic valve: the ' $\chi$-movement' removal technique and subsequent reimplantation. Interact Cardiovasc Thorac Surg. 2012; 15:280-281.

54. Murzi M, Cerillo AG, Bevilacqua S, et al. Traversing the learning curve in minimally invasive heart valve surgery: a cumulative analysis of an individual surgeon's experience with a right minithoracotomy approach 
for aortic valve replacement. Eur J Cardiothorac Surg. 2012;41: $1242-1246$.

55. Caffarelli AD, Robbins RC. Will minimally invasive valve replacement ever really be important? Curr Opin Cardiol. 2004;19:123-127.

56. Fenton JR, Doty JR. Minimally invasive aortic valve replacement surgery through lower half sternotomy. $J$ Thorac Dis. 2013;5: S658-S661.

57. Ranucci M, Frigiola A, Menicanti L, et al. Aortic cross-clamp time, new prostheses, and outcome in aortic valve replacement. J Heart Valve Dis. 2012;21:732-739.

58. Nijhoff F, Abawi M, Agostoni P, Ramjankhan FZ, Doevendans PA, Stella PR Transcatheter aortic valve implantation with the new balloon-expandable Sapien 3 versus Sapien XT valve system: a propensity score-matched single-center comparison. Circ Cardiovasc Interv. 2015;8:e002408.

59. Wendt D, Al-Rashid F, Kahlert P, et al. Low incidence of paravalvular leakage with the balloon-expandable Sapien 3 transcatheter heart valve. Ann Thorac Surg. 2015;100:819-826.
60. D'Onofrio A, Messina A, Lorusso R, et al. Sutureless aortic valve replacement as an alternative treatment for patients belonging to the "gray zone" between transcatheter aortic valve implantation and conventional surgery: a propensity-matched, multicenter analysis. $J$ Thorac Cardiovasc Surg. 2012;144:1010-1016.

61. Rubino AS, Santarpino G, De Praetere H, et al. Early and intermediate outcome after aortic valve replacement with a sutureless bioprosthesis: results of a multicenter study. $J$ Thorac Cardiovasc Surg. 2014;148: $865-871$.

62. Englberger L, Carrel TP, Doss M, et al. Clinical performance of a sutureless aortic bioprosthesis: five-year results of the $3 \mathrm{f}$ Enable long-term follow-up study. J Thorac Cardiovasc Surg. 2014;148:1681-1687.

63. Haverich A, Wahlers TC, Borger M, et al. Three-year hemodynamic performance, left ventricular mass regression, and prostheticpatient mismatch after rapid deployment aortic valve replacement in 287 patients. J Thorac Cardiovasc Surg. 2014;148:2854-2860. 